INTERPRETAÇÕES POLÍTIAS PÚBLICAS POR MULH EXTRATIVISTAS DE MANC EM SER 


\section{INTERPRETAÇÕES DE POLÍTICAS PÚBLICAS POR MULHERES EXTRATIVISTAS DE MANGABA EM SERGIPE}

DALVA MARIA DA MOTA

EMBRAPA AMAZÔNIA ORIENTAL, BRASIL

H E R I B E R T S C H M I T Z

UNIVERSIDADE FEDERAL DO PARÁ, BRASIL

NOEMI SAKIARA MIYASAKA PORRO

UNIVERSIDADE FEDERAL DO PARÁ, BRASIL

J O S U É F R A N C I S C O D A S I L V A J Ú N I O R

EMBRAPA TABULEIROS COSTEIROS, BRASIL

RAQUEL FERNANDES DE ARAÚJO RODRIGUES

EMBRAPA TABULEIROS COSTEIROS, BRASIL 


\title{
INTERPRETAÇÕES DE PROGRAMAS DE POLÍTICAS PÚBLICAS POR MULHERES EXTRATIVISTAS DE MANGABA EM SERGIPE
}

\section{Resumo}

O objetivo do artigo é analisar como os programas de políticas públicas que afetam as mulheres extrativistas de mangaba têm sido interpretados localmente. Os programas em análise são o Programa de Aquisição de Alimentos (PAA) e o Seguro-Desemprego do Pescador Artesanal, nos quais elas participam regular ou ocasionalmente. Foram realizadas observações e entrevistas com roteiro aberto e semiestruturado e os dados foram analisados à luz dos aportes teóricos da sociologia. Os resultados indicam que ambos os programas proporcionam melhoria no acesso à renda e na satisfação das suas afiliadas; diferenciam-se, entretanto, quanto ao uso dos recursos naturais, temporariamente interditado na pesca e estimulado no extrativismo da mangaba. Em relação aos sentidos, o PAA abriga relações mais próximas das mercantis, pois exige contrapartida contratual; o seguro-defeso é percebido localmente como uma relação assistencial, "uma ajuda" do governo para os pobres, com uma contrapartida que depende da consciência de cada um.

Palavras-chave: Programa de Aquisição de Alimentos, Seguro-Defeso do pescador artesanal, Catadoras de mangaba.

\section{INTERPRETATIONS OF PUBLIC POLICY PROGRAMS BY MANGABA GATHERER WOMEN IN SERGIPE}

\begin{abstract}
The objective of this paper is to analyze the local interpretations of public policy programs by mangaba gatherer women. The Food Acquisition Program (PAA) and the Insurance Program for Artisan Fishermen were assessed, regarding women with regular or occasional participation. Field observations and open and semi-structured interviews were carried out and analyzed in the light of the theoretical contributions of sociology. The findings indicate that both programs provide improved income and higher self-regard to the affiliates. They differ, however, regarding the use of natural resources: temporarily interrupted in the case of fishing and stimulated in the mangaba gathering. In relation to the local interpretations, the relationships promoted by the PAA are more market-like due to the contractual requirements. The Insurance for Fishermen is perceived locally as a welfare program, a sort of support from the government to the poor population, demanding however a return, which depends on the individual conscience.
\end{abstract}

Keywords: Food Acquisition Program, Insurance Program for artisan fishermen during the breeding season, Mangaba gatherer women. 


\section{INTERPRETACIONES DE PROGRAMAS DE POLÍTICAS PÚBLICAS POR MUJERES RECOLECTORAS DE MANGABA EN SERGIPE}

\section{Resumen}

El objetivo de este trabajo es analizar cómo han sido interpretados localmente los programas de políticas públicas que afectan a las mujeres recolectoras de mangaba. Los programas en cuestión son el Programa de Adquisición de Alimentos (PAA) y el Seguro de Desempleo del Pescador Artesanal ("Seguro-Defeso") en los cuales esas mujeres participan con regularidad o de vez en cuando. Se realizaron las observaciones y entrevistas con guión abierto y semi-estructurado y se analizaron los datos a la luz de las aportaciones teóricas de la sociología. Las conclusiones indican que ambos programas proporcionan mejor ingreso y satisfacción de sus afiliados. Difieren, sin embargo, con respecto al uso de los recursos naturales: prohibidos temporalmente en la pesca y estimulados en la recolección de mangaba. En relación a las interpretaciones locales, PAA es más estrechamente relacionado con el mercado, ya que requiere la contrapartida contractual. El "Seguro-Defeso" se percibe localmente como una relación asistencial, "una ayuda" del gobierno para los pobres, con una contrapartida que depende de la conciencia del individuo.

Palabras clave: Programa de Adquisición de Alimentos, Seguro de Desempleo del pescador artesanal, Recolectoras de mangaba.

Endereço da primeira autora para correspondência: Embrapa Amazônia Oriental - Trav. Dr. Enéas Pinheiro s/n n $^{\circ}$ Caixa Postal, 48 Belém, PA - Brasil CEP 66095-100. E-mail: dalva.mota@embrapa.br 


\section{INTRODUÇÃO}

$\mathrm{Na}$ última década, o debate sobre gênero e programas de políticas públicas tem enfatizado iniciativas específicas para as mulheres que vivem no espaço rural no Brasil. Os movimentos de mulheres rurais que atuam fortemente têm papel de destaque nesse debate, "tanto na correção de rumos das políticas e na garantia de efetivação do acesso das mulheres aos direitos conquistados, como também no impulsionamento de mudanças culturais e de autopercepção do lugar das trabalhadoras das áreas rurais como atores sociais e políticos" (Heredia \& Cintrão 2006: 21). As autoras analisam que os movimentos específicos de mulheres são recentes, mas dinâmicos e com influência no estabelecimento de um quadro político institucional. Esse quadro tem sido marcado tanto pela institucionalização de movimentos mais gerais, quanto pelo surgimento de organizações associadas às identidades e questões específicas como o Movimento das Quebradeiras de Coco-Babaçu, o Movimento das Mulheres Pescadoras e a Organização das Mulheres Quilombolas, na década de 1990. Nesse processo, afirmam as autoras, "a organização e as mobilizações das mulheres trabalhadoras rurais trouxeram ao Estado um conjunto de reivindicações, colocando a necessidade de dar respostas às questões colocadas" (op.cit.: 11). ${ }^{1}$ Mesmo assim, críticas persistem quanto à limitada influência das políticas públicas no aumento da satisfação e do bem-estar das mulheres rurais (Paulilo 2012), particularmente daquelas que não têm acesso regular aos recursos naturais dos quais dependem para sobreviver, como as extrativistas de produtos vegetais e animais que vivem no espaço rural no Brasil (Mota et al. 2012).

Neste artigo analisamos situações nas quais as mulheres reivindicam novas posições em busca do reconhecimento associado à equidade com direito à diferença, quer seja na forma de gestão do recurso natural, quer seja no modo de viver as relações sociais de gênero (Porro et al. 2011). Nas reivindicações que fazem, o tema das políticas públicas é constante, o que nos instigou a questionar: como os programas de políticas públicas têm sido interpretados localmente pelas mulheres extrativistas? Para responder a essa pergunta, realizamos um estudo de caso no povoado Pontal no município de Indiaroba (SE), Nordeste do Brasil (Figura 1), onde mulheres extrativistas de mangaba (Hancornia speciosa) participam simultaneamente dos dois programas, sendo o PAA a primeira experiência dessa natureza no país.

A pesquisa foi feita com lideranças, mediadores e mulheres extrativistas que lidam, simultaneamente, com o Programa de Aquisição de Alimentos (PAA) e com o Seguro-Desemprego do Pescador Artesanal (seguro-defeso). A escolha desses programas ${ }^{2}$ tem relação com os seus diferentes incentivos quanto ao uso dos recursos, pois o primeiro depende da disponibilidade e da acessibilidade do fruto da mangabeira para a comercialização no âmbito do programa, e o segundo interdita a atividade de coleta no manguezal no período de reprodução do camarão.

No que diz respeito à metodologia, observações diretas e entrevistas com 

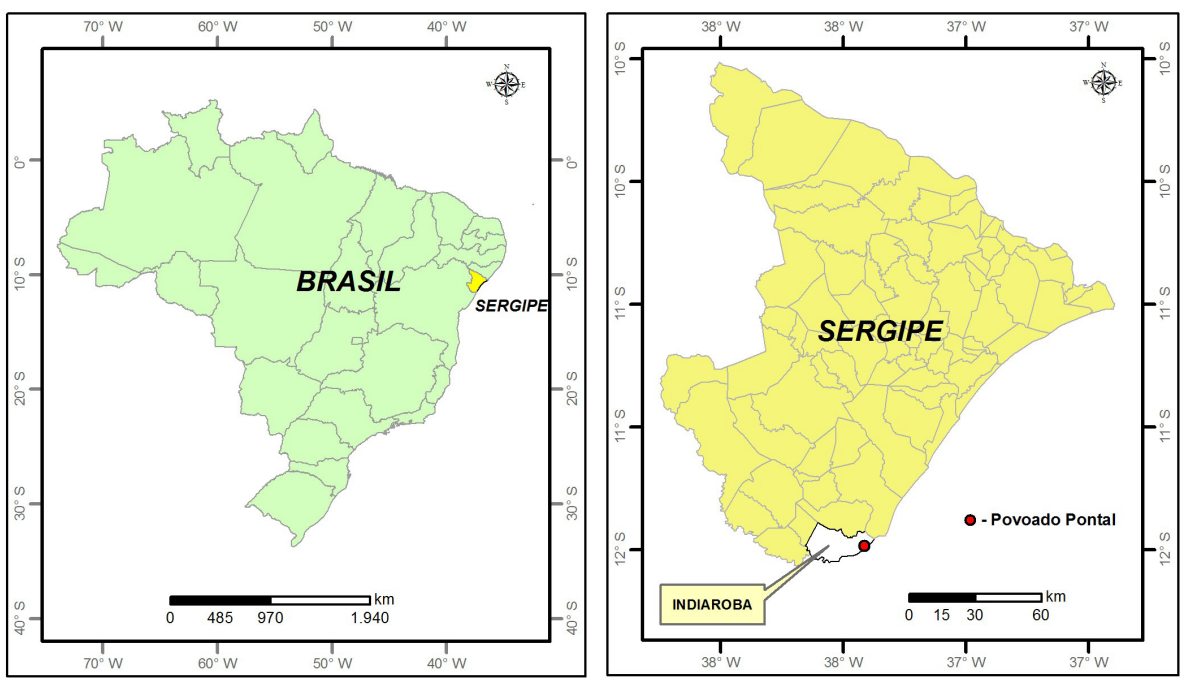

Figura 1 - Mapa da localização do povoado Pontal (município de Indiaroba, Estado de Sergipe, 2012). Fonte: Rocha.

roteiro aberto e semiestruturado foram realizadas, e os dados analisados à luz dos aportes teóricos da sociologia e da antropologia social. A importância do tema atrela-se ao fato de que leis e programas têm sido implantados especificamente ou com destaque para mulheres que vivem no espaço rural no Brasil nas três últimas décadas, ${ }^{3}$ sugerindo novos termos em relação às estratégias que são postas em prática cotidianamente por pessoas cujo sustento depende dos recursos naturais, atualmente em crescente escassez.

\section{AFILIAÇÕES E INTERPRETAÇÕES LOCAIS: PAA E SEGURO-DEFESO}

Neste artigo tratamos de mulheres extrativistas de mangaba e de produtos do manguezal autodesignadas catadoras de mangaba e marisqueiras, ${ }^{4}$ respectivamente. Elas são portadoras de uma identidade coletiva ligada a recursos de uso comum com baixo impacto ambiental (Castro 1997; Mota et al. 2011a) e, recentemente, reconhecidas formalmente como pertencentes a um grupo culturalmente diferenciado (Mota et al. 2011b). Em contraste, enfrentam uma crescente diminuição dos recursos, nos quais praticam o extrativismo, em decorrência da privatização das áreas e do corte das plantas por empresários e citadinos para outros fins, como agricultura, pecuária, carcinicultura e implantação de infraestruturas turística e imobiliária (Schmitz et al. 2010).

A diminuição do acesso aos recursos e a maior concorrência por eles, em razão do aumento populacional no final da década de 1980 e a privatização das áreas (intensificada após a mobilização política das catadoras de mangaba a partir de 2007) coexistem com o maior acesso das catadoras a programas de políticas públicas que, reconhecidamente, contribuem para garantir boa 
parte do necessário à sobrevivência. Refletir sobre as interpretações locais desses programas é o nosso desafio neste artigo.

\section{PONTAL: ENTRE A TERRA, O RIO E O MAR}

A memória oral registra que o arruamento do Pontal principiou há cerca de 90 anos. Inicialmente foram construídas barracas de palha pelos pescadores, que as utilizavam como ponto de apoio para os intervalos das jornadas de pesca. Pouco a pouco, elas foram sendo substituídas por casas de taipa. ${ }^{5}$ Nos arredores, situavam-se estabelecimentos sob o domínio das famílias consideradas fundadoras, que detinham a sua posse desde o século XIX, como indicam os estudos sobre os engenhos em Sergipe (Almeida 1991). As atividades dessas famílias eram, principalmente, a criação de gado e a exploração de coqueiros em áreas de ocorrência natural de mangabeiras. Como em outras partes do Nordeste, as culturas alimentares eram produzidas em áreas cedidas pelos seus proprietários a partir de relações de parentesco, camaradagem e compadrio, em um sistema de reciprocidades e trocas entre os que tinham diferentes formas de acesso à terra.

Entrevistados mais idosos afirmam que até os anos 1970-1980, essas áreas pertenciam a seis famílias. Recentemente, constatamos mudanças decorrentes da segmentação das áreas por processos de herança e da venda, sobretudo após a intensificação do turismo. Os entrevistados afirmam também que havia ali uma práti- ca comum - a doação de lotes pelos proprietários de terra para a construção de casas pelos que não possuíam nenhum terreno, como também para outros fins, como a construção do primeiro prédio escolar nos anos 1950. Reconhecem que o Pontal, pela facilidade de acesso a recursos vegetais e animais, por situar-se nas margens de um estuário, sempre atraiu novos moradores das circunvizinhanças, que também constituíam vínculos por meio de casamento.

Constatamos que um marco importante na intensificação do povoamento foi a filmagem da novela "Tieta do Agreste", em 1989-1990, que alçou o Pontal à condição de porto para todos que queriam tomar uma embarcação e conhecer a praia de Mangue Seco, onde ocorriam as filmagens. Assim, pequenos comércios foram estabelecidos, atraindo novos moradores. Mais recentemente, investimentos públicos voltados principalmente para o turismo na região, como pontes e asfaltamento de estradas secundárias, têm contribuído para a valorização da terra e, consequentemente, para a diminuição da disponibilidade dos recursos. O cercamento de áreas anteriormente livres para a coleta de frutos, privatização das margens de rios e o loteamento de novas áreas têm ocasionado disputas e novas relações entre moradores antigos e recentes.

Após cruzarmos informações da Embrapa (Vieira \& Rodrigues 2009: 28) e do agente de saúde do povoado, avaliamos que, em 2013, vivem no Pontal cerca de 250 famílias, cujos membros se dedicam a um conjunto diversificado de 
atividades, dentre as quais podemos citar o extrativismo "no mar e na terra".

Duas ruas situadas paralelamente, das quais derivam perpendicularmente as demais, compõem o povoado. A primeira, denominada localmente Rua da Frente, porque localiza-se em frente ao rio Real, oficialmente se chama Rua Francisco Alves Torres. A segunda, imediatamente atrás, chama-se Rua de Trás, por oposição à primeira. Não oficialmente, essa rua tem dois nomes: Rua do Campo e Rua da Alegria. Perpendicularmente a esta última rua estão as Ruas do Cemitério, das Mangabeiras e da Escola. É importante observar que espaços de uso comum (cemitério, mangabeiras e escola) influem na denominação das ruas. Nos últimos cinco anos, entretanto, parte das mangabeiras ali existentes foi cortada para ceder lugar a casas dos próprios moradores, algumas construídas com recursos do Programa Nacional de Habitação Rural (PNHR), do Governo Federal. Persiste nas proximidades dessa rua uma área privada, mas de acesso livre, com aproximadamente 5.000 pés de mangaba, cuja proprietária nos afirmou em entrevista: "deixe lá para quem precisa que eu não vou tirar o pão da boca do povo".

O povoado tem três igrejas (uma católica e duas evangélicas), abastecimento de água, posto de saúde, uma escola e um clube. Quanto à organização social formal, existem duas associações: Associação dos Moradores do Povoado Pontal e Periferia e Associação das Catadoras de Mangaba do Município de Indiaroba (ASCAMAI). As mulheres extrativistas são afiliadas também às
Colônias de Pescadores Z4 (a maioria) e Z11, com sedes nos municípios de Estância e Indiaroba, respectivamente.

No que concerne ao extrativismo vegetal no Pontal, chama a atenção a referência histórica de todos os entrevistados ao sistema de acesso comum aos recursos naturais em áreas públicas e privadas. Segundo informam, nas áreas privadas, os proprietários da terra ou seu representante permitiam o acesso de certas catadoras. A partir de 2007, com a participação das catadoras de mangaba em circuitos formais de comercialização, via PAA, e com a valorização da mangaba no mercado de produtos frescos mediante a valorização do consumo de produtos saudáveis, essas relações sofreram alterações, e permissões são cada vez mais raras, porque os proprietários temem ter as suas áreas desapropriadas ou não concordam com a comercialização de frutos coletados gratuitamente em seus estabelecimentos. Em relação ao extrativismo animal, áreas de pesca têm sido interditadas por meio dos viveiros de camarão, cujos proprietários privatizam as margens dos rios e áreas de manguezal. Nas duas situações, concepções opostas coexistem, para as extrativistas, os frutos e os mariscos são de todos, porque não são produtos do trabalho de ninguém e foram criados por Deus; para os proprietários, os frutos e mariscos pertencem a quem detém a propriedade da terra ou das margens dos rios. Tais concepções reacendem o debate sobre a propriedade privada, concebida, por um lado, como fruto do trabalho e, por outro, como resultado da apropriação privada 
da terra. Esses contrastes também foram identificados por Cardoso (2008) entre os povos quilombolas e os fazendeiros da Ilha de Marajó, Estado do Pará.

Em 2013, constatamos que o extrativismo vegetal (mangaba) e animal (pesca e coleta de moluscos e crustáceos), como siri (Callinectes danae), caranguejo (Carcinus maenas), aratu (Aratus pisonii), sururu (Mytella falcata) e ostra (Crassostrea rhizophorae) persistem como as principais atividades das mulheres extrativistas no Pontal. Rocha (2012) constatou que, até o momento da sua pesquisa, em 2010, o extrativismo da mangaba era praticado em áreas de livre acesso por todas as 42 extrativistas por ela entrevistadas - cinco das quais também coletavam em áreas pertencentes a suas famílias. Nas áreas de acesso livre, a gestão estava amparada nas regras consuetudinárias que naquele momento, começavam a ser desrespeitadas e, ao mesmo tempo, questionadas. Em nove estabelecimentos, as catadoras de mangaba seguiam os ditames dos proprietários. $^{6}$

Em todas essas situações, entretanto, registramos tensões provocadas pela desproporção entre o número de extrativistas e a diminuição dos recursos em um contexto de maior acesso à programas de políticas públicas. As tensões foram alimentadas também, pela interrupção da participação no PAA em 2011 e pelos problemas de várias mulheres no processo de afiliação ao seguro-defeso.

\section{O PAA NO PONTAL}

O $\mathrm{PAA}^{7}$ foi constituído pelo Governo Federal, em 2003, como uma das ações estruturantes do Programa Fome Zero e tem como objetivo central "garantir o acesso aos alimentos em quantidade, qualidade e regularidade necessárias às populações em situação de insegurança alimentar e nutricional, e promover a inclusão social no campo por meio do fortalecimento da agricultura familiar" (CONAB 2007). O programa apoia simultaneamente a compra e a venda de alimentos dos agricultores familiares ${ }^{8}$ com incentivos, inclusive à participação nos circuitos formais de comercialização, visando promover a produção de alimentos na agricultura familiar e a comercialização para o mercado institucional (Delgado et al. 2005).

Segundo Grisa et al. (2009), o quadro geral que originou esse tipo de iniciativa foram os debates sobre a problemática da segurança alimentar e nutricional nas últimas três décadas e o reconhecimento da importância da agricultura familiar no Brasil, com a criação do Programa Nacional de Fortalecimento da Agricultura Familiar (Pronaf) em 1996 e, mais recentemente, em 2006, com a promulgação da Lei n. ${ }^{\circ} 11.326$ que estabelece as diretrizes para a formulação da política nacional da agricultura familiar e dos empreendimentos familiares rurais, como por exemplo, o extrativismo.

Para Müller et al. (2007), o PAA inscrevese em um campo de ação que é demarcado, de um lado, pelas ações da política agrícola de formação de estoques e compra de produtos agrícolas, realizadas pela Companhia Nacional de Abastecimento (Conab), e de outro, pelas iniciativas do Programa Fome Zero, que buscam 
ampliar o acesso a alimentos por meio de mecanismos de subvenção às compras e de redistribuição às entidades que trabalham com populações em situação de risco ou de vulnerabilidade alimentar, como asilos, orfanatos, escolas e creches.

No escopo do PAA, destaca-se a aquisição direta de alimentos de produtores familiares com dispensa de licitação para a doação a instituições e pessoas em situação de insegurança alimentar e nutricional ou para a formação de estoques estratégicos e o abastecimento do mercado institucional de alimentos, que compreende as compras governamentais de gêneros alimentícios para diversos fins. O programa permite que os agricultores familiares estoquem os seus produtos para serem comercializados a preços mais justos (Siliprandi \& Cintrão 2011).

No próximo tópico, refletiremos sobre a participação das mulheres extrativistas no PAA, por meio de duas ações: a venda da mangaba oriunda do extrativismo pelas catadoras de mangaba e a recepção, por todos os habitantes, de produtos alimentares vindos de agricultores. A mediação dá-se no âmbito do PAA, o programa gerenciado pela Conab.

\section{O PAA LEVA A MANGABA PARA FORA DO PONTAL}

A primeira ação refere-se à participação de um grupo de catadoras de mangaba no PAA a partir de 2007, após mediadores ${ }^{9}$ terem divulgado o PAA em uma reunião com 28 catadoras de mangaba no Pontal, em 2006. Na sequência, eles encaminharam uma proposta à Conab, para a inclusão da fruta no programa. Houve uma adesão inicial de seis catadoras em 2007 e 2008, de 20 em 2009 e 2010 e de 30 em 2011. Segundo entrevistados, a baixa adesão inicial deveu-se à falta de informação Sobre o PAA, ao receio de perder o seguro-defeso que tinham na condição de marisqueiras e ao fato de que estavam informadas de que o pagamento só ocorreria após 30 dias, diferentemente do que ocorria quando vendiam aos intermediários e recebiam o dinheiro no ato da comercialização.

Esses receios agravaram-se por causa de uma polêmica na mobilização para o I Encontro das Catadoras de Mangaba em 2007, quando lideranças locais disputaram a afiliação das extrativistas. Para uns, elas eram exclusivamente marisqueiras (categoria êmica para designar a extrativista de recursos aquáticos) e a insistência em identificar-se como catadoras de mangaba, poderia fazer com que não tivessem mais o segurodefeso. Para outros, catadora e marisqueira eram designações que poderiam ser utilizadas para identificar todas as mulheres, porque as atividades são desenvolvidas por elas, "cada uma no seu tempo" e segundo arranjos variados. Estava em questão, o balanço entre as atividades, concepção que persiste até o presente momento, pois, em abril de 2013, questionado sobre o direito das catadoras de mangaba de receber o seguro-defeso, o responsável pela Colônia de Pesca Z4 respondeu: "[Elas] podem, não tem problema nenhum. Mas, se a mangaba for responsável por maior parte de sua sobrevivência, 
ela perde o seguro" (J. M. R., 66 anos, presidente da Colônia Z4).

Embora a legislação exclua outras atividades econômicas que não a pesca, não existem regras formais que explicitem o percentual máximo permitido de produção agrícola ou de extrativismo vegetal na composição da renda da marisqueira e que ainda permita o seu acesso como pescadora artesanal ao seguro. Além disso, não existem condições para uma averiguação junto aos candidatos ao benefício.

A modalidade do PAA a que as catadoras tiveram acesso foi a Compra Antecipada Especial da Agricultura Familiar (CAEAF), ${ }^{10}$ com doação simultânea às instituições localizadas no município ou nas proximidades. ${ }^{11} \mathrm{~A}$ instituição, por meio da qual as catadoras participaram do PAA foi a Cooperativa de Produção, Comercialização e Prestação de Serviços dos Agricultores Familiares de Indiaroba e Região (Cooperafir), afiliada à Associação de Cooperação Agrícola dos Assentados da Região Sul (Ascosul), que tanto possui membros individuais como também exerce o papel de uma central articuladora de associações.

Para participar do programa, a catadora deveria estar associada à cooperativa, possuir a Declaração de Aptidão ao Pronaf (DAP), obtida no escritório mais próximo da Empresa de Desenvolvimento Agropecuário de Sergipe (Emdagro) e ser reconhecida como extrativista pelos articuladores locais (lideranças das catadoras e mediadores). Dada a dificuldade que algumas catadoras tiveram para obter a DAP por não disporem da documentação exigida, por não terem recursos para deslocarse ou mesmo por não considerarem necessária a obtenção do documento, arranjos foram feitos localmente para incluir essas catadoras na comercialização das frutas. Assim, elas participavam por intermédio daquelas que tinham DAP, o que evidencia a solidariedade e a confiança para lidar com um entrave burocrático novo na história do grupo. A partir dessa iniciativa, cerca de 70 mulheres comercializaram as suas frutas no PAA na última participação das catadoras de mangaba, que ocorreu em 2011. A suspensão da participação nesse ano decorreu da insatisfação dos recebedores com a qualidade dos frutos.

Tal interrupção não é claramente explicada pelas catadoras entrevistadas, que atribuem o fato a um problema burocrático, mas em nenhuma situação à qualidade dos frutos. Entretanto, em observação de uma das entregas em 2011, constatamos que a forma de acondicionamento dos frutos e os diferentes estágios de maturação implicavam perda de qualidade, agravada pelo fato de o fruto ser muito perecível. $\mathrm{Na}$ ocasião, conversas informais fizeramnos entender que havia muitas reclamações das entidades que recebiam os frutos em relação à qualidade. À medida que o volume comercializado de frutas aumentou, esse tipo de controle parece ter ficado mais difícil para os mediadores.

O funcionamento do PAA no dia a dia era articulado por um mediador local, ${ }^{12}$ que voluntariamente organizava as entregas, pesava os produtos, anotava o quantitativo de cada catadora e executava 
todas as tarefas burocráticas perante as demais instituições, além de tentar controlar a qualidade dos frutos. O mediador regional (vereador e membro da Ascosul) atuava como articulador quanto à destinação dos frutos e aos contatos com a Conab. A divulgação de datas de eventos relativos ao PAA, particularmente as "entregas", era feita pelas lideranças e pelas próprias catadoras.

Do total de catadoras de mangaba que comercializava frutos oficialmente no PAA em 2011, 87\% tinham as suas próprias DAP. Não obstante o Programa destacar explicitamente a importância da participação das mulheres, em $13 \%$ das DAP constava os nomes dos maridos por opção dos responsáveis pelo cadastramento que levaram em consideração as relações formalizadas com certidão de casamento, embora o Código Civil brasileiro considere a igualdade entre os cônjuges. Diferentemente dessa situação, Siliprandi e Cintrão (2011) evidenciaram a predominância da participação dos homens, em contraste com o anonimato das mulheres em outros lugares do Brasil. As autoras analisam que, via de regra, o homem é considerado o chefe da família pelo corpo burocrático das instituições envolvidas no programa.

Nesse particular, as catadoras de mangaba de Sergipe tinham a seu favor uma tradição cultural que associa o extrativismo de mangaba ao trabalho das mulheres, predisposição mobilizada na constituição de sua identidade coletiva (Mota et al. 2011b).

Apesar de terem participado durante cinco anos do PAA na condição de fornecedoras e de continuarem partici- pando como receptoras, as mulheres extrativistas entrevistadas sabem descrever o programa, mas demonstram não entender as razões da suspensão das entregas. Constam em suas explicações, os prérequisitos para participar do programa, os dias de "entrega" e de recepção, o preço por quilo dos frutos e os consumidores que os receberão. Nas entrevistas que realizamos em 2011, elas manifestaram sua preocupação com a qualidade dos frutos a serem entregues, pois estavam informadas do poder dos receptores para definir a continuidade delas no programa, segundo a avaliação desse requisito.

A comercialização dos frutos a um preço fixo no PAA gerou segurança quanto ao dinheiro que seria recebido e, consequentemente, aos compromissos financeiros que poderiam ser assumidos. Em depoimentos registrados em 2010, as catadoras afirmaram:

"O meu ganho maior hoje é da mangaba, vendendo na Conab, aqui mesmo, como você viu, aí, a gente tira, chega em casa é só cuidar, lavar direitinho. No dia da entrega pega, leva e entrega. [...] E agora não tem nem comparação, né?” (A. S., presidente da Associação das Catadoras de Mangaba de Indiaroba - Ascamai).

"A pessoa tira a mangaba, pesa e tem o dinheiro certo" (E. M. C., 46 anos, catadora de mangaba).

"A vida continua a mesma, o que mudou foi o prestígio, porque todo mundo me conhece como a menina da mangaba, mas eu sou sozinha, aí não cata tanto. Mudou porque tem a pessoa certa para entregar [a Conab]” (A. C. O. S., 22 anos, catadora de mangaba). 
Como pode ser analisado, estava em jogo não apenas a disponibilidade de renda, mas também o reconhecimento social. Além disso, a participação no PAA significou uma oportunidade para as mulheres que enfrentam problemas de saúde para continuar "mariscando", o que é considerado um trabalho muito árduo, como informa uma delas:

"Foi quando surgiu esse projeto da mangaba que a gente entregava pro PAA. E é isso, continua nisso. Porque pescar eu não posso mais, a gente pesca até uma idade, né? Depois as pernas não dão, né? Aí parte pra outra coisa da mangaba" (L. C. S., 61 anos, extrativista).

Ademais, a participação no PAA influiu no preço, porque estabeleceu um patamar que os intermediários não consideravam vantajoso pagar, como informa uma pequena comerciante:

"Eu mesma deixei de negociar com a mangaba, porque a concorrência do PAA alterou os preços no local. Ninguém mais queria entregar, porque o PAA até pagava mais. Os carros também deixaram de entrar [no Pontal]” (K. R. S. L., 33 anos, marisqueira e comerciante).

Depoimentos indicam que o PAA influenciou a própria percepção da condição social das catadoras de mangaba, porque elas afirmaram ter maior acesso à renda e ao reconhecimento social. Contas atrasadas foram pagas, alimentos consumidos raramente, como a carne, passaram a ser consumidos com maior frequência e mais da metade das casas das entrevistadas foi reformada. Entretanto, elas não sabem explicar o mo- tivo da interrupção, nem têm perspectiva de retorno.

"Era bom que a gente entregava mangaba [...] Eu fiz um dinheirinho na Conab quando a gente entregava mangaba. Essa daqui saia mais o pai pra pegar lá na ribeira, daí a gente fazia um dinheirinho, era bom, mas acabou o projeto, foram mudar pra estoque, não sei que estoque foi esse, perdemos muita mangaba. Hoje em dia nem faço mais questão da Conab, hoje a gente vende bastante" (J. S., 45 anos, extrativista de mangaba).

A indicação do depoimento da entrevistada acima quanto à participação em uma nova modalidade (estoque) coincide com a informação dada por lideranças que articulam o PAA regionalmente. Para 2014, a Ascosul está propondo que as catadoras migrem para o PAA Estoque. Isso significa comercializar frutos in natura para serem transformados em polpa, cujo quilo é vendido a $\mathrm{R} \$ 2,80$. O projeto elaborado pela Ascosul prevê a contratação de uma fábrica para beneficiar e embalar o produto no estilo longa vida. Nesse caso, o produto chegará aos consumidores beneficiários na forma de suco.

\section{O PAA TRAZ COMIDA PARA O PONTAL}

A segunda ação no âmbito do PAA analisada neste artigo trata do recebimento de alimentos por todos os habitantes do Pontal. São produtos agrícolas comprados pela Conab de agricultores da circunvizinhança para a distribuição a grupos em situação 
de insegurança alimentar, do mesmo modo que ocorria com as mangabas vendidas pelas catadoras do Pontal, que eram doadas a instituições. Produtos como laranja, melancia, mandioca, macaxeira, coco verde e hortaliças fazem parte do elenco.

Os momentos de recebimento são aguardados com expectativa, segundo informaram algumas entrevistadas, tanto pela efervescência provocada pelo evento no Pontal, quanto pelo fato de a família poder dispor de alimentos diferenciados por alguns dias. Eles têm sido previamente agendados com uma liderança e a informação circula de "boca em boca" entre os moradores. Essa mesma liderança, que coordenava as atividades relativas à comercialização da mangaba no PAA, organiza o trabalho de descarga e a organização das frutas na sede da associação de moradores. Além disso, requisita jovens do sexo masculino para distribuílas, o que caracteriza uma divisão do trabalho, em que compete aos homens (mesmo que mais jovens) entregar os alimentos que serão levados pelas mulheres para serem consumidos na esfera doméstica. Estas últimas, munidas de sacos, sacolas e carrinhos de mão formam filas à espera da sua parte.

Observamos que no interior do clube, frutos arrumados e separados tinham lugares específicos, conforme um sistema de distribuição criado localmente. As laranjas eram medidas em baldes, os cocos e mamões por unidade, a melancia por fatias e as cebolinhas em molhos.

O presidente da associação usa um megafone para dar avisos e organizar a distribuição. Uma fila de mulheres, maduras e jovens, forma-se de dentro para fora do clube. As pessoas eram chamadas de três em três para receber os produtos, devidamente contabilizados para atender a todos os residentes. O papel das crianças é "ajudar" suas mães, avós ou irmãs. Assim, forma-se na frente do clube um entra e sai de pessoas carregando o que receberam nas mãos, em bicicletas, carrinhos de mão ou na cabeça. Algumas crianças já experimentam as frutas ali mesmo.

Diferentemente da comercialização da mangaba, que incluía apenas quem coletava os frutos, a distribuição de alimentos é feita de modo indiscriminado a todos os que residem no Pontal, independentemente da sua condição financeira. Essa "universalidade" parecia ser bem aceita entre os que ali estavam, provavelmente, por tratar-se de alimentos que, segundo noções preexistentes, nunca devem ser negados aos que vivem no mesmo espaço. Diferentemente, críticas são tecidas aos que recebem o dinheiro do seguro-defeso sem serem reconhecidos como marisqueiras ou pescadores experientes.

Em nossa opinião, as duas medidas são diferentes por sua natureza. Enquanto o recebimento de alimentos pelo sistema de doação simultânea do PAA - nesse caso, pela distribuição de alimentos a todos os moradores de Pontal organizada pela Associação de Moradores do Povoado Pontal e Periferia - assemelha-se mais a medidas convencionais da assistência social, o seguro-defeso é um programa de transferência direta de renda com condicionalidades (existência da DAP, 
comprovação da condição de pescador ou de marisqueira e respeito à regra que interdita a atividade de coleta no manguezal no período de reprodução do camarão). No entanto, uma questão-chave para a avaliação das políticas públicas consiste em verificar se elas promovem a solidariedade ou se estigmatizam aqueles que delas precisam (Fraser 2003: 116). No caso em estudo, é a falta de cumprimento das condicionalidades que provoca as críticas e não o recebimento do benefício, mesmo por pessoas que dele não necessitam, o que promove, portanto, a solidariedade.

\section{O SEGURO-DEFESO DO PESCADOR ARTESANAL}

Como analisam Lourenço et al. (2006), o seguro-defeso é um benefício definido a partir da inclusão plena dos trabalhadores rurais $^{13}$ no sistema previdenciário oficial. A sua efetivação ocorreu com a promulgação da Lei n. ${ }^{\circ} 8.213$, de 25 de julho 1991, que incluiu os pescadores artesanais entre os segurados especiais, considerados aqueles que, "individualmente ou em regime familiar", fazem da pesca sua "profissão habitual ou principal meio de vida", desde que respeitadas algumas outras características. Também passam a ser possíveis segurados especiais, o cônjuge e os filhos maiores de 16 anos de idade, desde que comprovem o exercício da atividade.

Segundo os autores, a política que instituiu o seguro-defeso está intrinsecamente ligada à que culminou com a equiparação dos direitos de trabalhadores rurais aos dos trabalhadores urbanos, obtida a partir da Constituição de 1988, na qual "os pescadores artesanais conquistaram avanços no que tange aos direitos sociais e políticos, quando as colônias de pescadores, através do Artigo $8^{\circ}$, foram equiparadas aos sindicatos de trabalhadores rurais, recebendo a configuração sindical” (Moraes 2001: 1). Tais políticas estenderam aos trabalhadores rurais benefícios sociais que eram, a princípio, exclusividade dos trabalhadores urbanos (Teixeira \& Abdallah 2008). Para isso, concede aos pescadores um salário mínimo a cada mês em que eles estejam impedidos legalmente de realizar a sua profissão, para suprir suas necessidades durante a época do defeso.

As primeiras afiliações dos residentes no Pontal ao seguro-defeso datam da segunda metade dos anos 2000 e foram incentivadas pelo presidente da Colônia de Pesca Z4 de Estância, que reside no povoado. Segundo informam mulheres entrevistadas, "ele avisou a uma e a outra da existência do benefício"; "fiquei sabendo por Zé Moraes" e, assim, elas prepararam os documentos, pagaram as taxas devidas e se candidataram. $\mathrm{Na}$ maior parte dos casos, obtiveram o seguro-defeso no primeiro ano de cadastro, mas nos anos subsequentes houve interrupção para muitas delas por problemas com a documentação. O presidente da Z4 informou que existiam 113 afiliados ao seguro-defeso no Pontal em abril de 2013. As mulheres predominam, aproximando-se de $70 \%$ do total.

Em relação à noção do defeso, nos depoimentos de mulheres extrativis- 
tas, afiliadas ou não ao seguro-defeso, predomina a expressão "defeso". Para umas, trata-se de um programa de política pública; para outras, é uma etapa do ciclo de reprodução das espécies. Em poucos casos, a junção das duas ideias prevalece, como mostram os depoimentos:

"É um dinheiro que as marisqueiras e pescadores recebem para não ir para a maré pegar camarão. Pode pegar peixe, mas só depois que eles desovam" (K. R. S. L., 33 anos, extrativista e pequena comerciante de produtos locais).

"O defeso é uma ajuda para os pescadores e nada mais” (J. C. P.A, 53 anos, pescador).

"É por conta das épocas que não pode pegar caranguejo, três meses que não pode pegar, camarão também são três meses, então é pra isso, pra esses meses que a gente não pode pegar, nem o camarão, nem o caranguejo" (J. S., 45 anos, extrativista).

Nos depoimentos acima, os entrevistados apresentam os diferentes sentidos que a palavra "defeso" assume na esfera local, evidenciando a sua complexidade em decorrência da interdição de uma espécie em um contexto em que muitas outras estão sob ameaça de esgotamento também e têm o seu período de defeso específico determinado, mesmo sem o seguro referir-se a elas. O primeiro e o último entrevistado fazem alusão ao conteúdo da legislação, na qual o defeso é "a paralisação temporária da pesca para a preservação da espécie, tendo como motivação a reprodução e/ou recrutamento, bem como paralisações causadas por fenômenos naturais ou acidentes". ${ }^{14}$

Os depoimentos referem-se, em parte, ao programa de política pública seguro-defeso, que o Instituto Brasileiro do Meio Ambiente e dos Recursos Naturais Renováveis (IBAMA) define de acordo com as particularidades das espécies e das regiões do país. Moreira et al. (2010: 2) explicam:

"Este benefício visa, a um só tempo, suprir as necessidades sociais dos pescadores artesanais durante a época do Defeso, quando ficam impossibilitados de pescar de acordo com a legislação [do] IBAMA e, ainda, estimulá-los a preservarem a natureza, na medida em que protegem áreas de grande afluência de desova e permitem a reprodução dos peixes, impedindo os impactos negativos na pesca para o consumo próprio e para a comercialização.”

Em alguns casos, os entrevistados tratam do seguro-defeso como uma política social de auxilio à sobrevivência dos mais pobres, que dependem da extração de recursos naturais escassos para viver. Tal compreensão parece estar relacionada ao fato de que houve uma degradação intensa dos recursos, ocasionada pelos viveiros de camarão e por uma empresa de piscicultura instalada nos arredores:

"Não sei o que está acontecendo, se são esses viveiros de camarão, que põem a bomba d'água na maré, vem resto de ração e essas coisas que eles põem, tanto o aratu, como o caranguejo se acabaram no mangue. Agora que está aparecendo. Antigamente a gente pegava 
dois centos de aratu rapidinho e ia embora pra casa, hoje tem que passar um tempão sentado no pesqueiro e não vê nada. Quando vê dois miudinhos correndo, pode pegar, se não vai embora pra casa sem nada... Nem sei, acho que é o tempo, as coisas estão sumindo da terra, tirador de caranguejo reclama que não tem, as marisqueiras reclama que não tem, minhas irmãs reclamam que não, e elas são as maiores marisqueiras daqui”" (J. S., 45 anos).

"A empresa chegou e foi invadindo. Esbagaçaram o mangue e forçaram a venda das terras [...] Contrataram alguns pescadores daqui. A droga usada nos cativeiros mata tudo" (J. C. P. A., pescador, 53 anos).

Nos depoimentos dos entrevistados, entre os quais os dois presidentes das Colônias de Pescadores Z4 e Z11, há frequentemente menção a um produto químico utilizado na limpeza dos tanques dos viveiros de camarão. Segundo os entrevistados, esse produto levou à redução dos caranguejos e camarões que vivem no manguezal e, consequentemente, afetou bastante a produção das marisqueiras. Os entrevistados referem-se especificamente a uma empresa de grande porte, que recentemente foi desativada. O presidente da Colônia Z11 relata ainda que, depois da desativação do empreendimento não foi mais observada a mortandade dos caranguejos e camarões nas áreas afetadas pelas descargas dos efluentes dos viveiros. Esses depoimentos coincidem com resultados de pesquisas sobre o impacto ambiental da carcinicultura, segundo os quais, na maioria dos empreendimentos, não é realizado um monitoramento dos efluentes, sendo mencionado especialmente "[...] $\mathrm{O}$ descarte do Metabissulfito de Sódio (antioxidante utilizado para prevenir o escurecimento dos camarões após serem despescados) [...] de maneira inadequada, não sendo realizados os procedimentos de armazenamento e tratamento recomendados pela ABCC $" 15$ (Joventino 2008: 198). Em Sergipe constata-se que, "[...] na maioria dos empreendimentos analisados, não há tratamento adequado dos resíduos dos viveiros antes que sejam lançados no estuário adjacente" (Carvalho \& Fontes 2007: 109). Além disso, a ocupação e a retirada da vegetação do manguezal para a implantação do viveiro diminuem significativamente a área acessível para o extrativismo animal.

Ademais, as mulheres extrativistas enfrentam também o problema da ampliação do número de pescadores nos últimos anos, seja pela falta de ocupações localmente, seja pelo atrativo exercido pelo seguro-defeso ou ainda pelo incentivo do Governo Federal à compra de barcos e equipamentos por pessoas que não são pescadores: "O número de pescadores aumentou muito, porque o seguro-defeso funciona como um atrativo. Também não tem opção. Antigamente dava muito marisco, eu vendia na feira muito, agora não tem" (E. A. M., 43 anos, extrativista, comerciante).

Os diferentes motivos para explicar a dificuldade de dispor de recursos naturais estão relacionados com uma questão que parece essencial para os entrevistados: a polêmica sobre quem 
teria direito ao seguro-defeso. $\mathrm{O}$ debate não é recente e envolve todos aqueles que desenvolvem múltiplas atividades distribuídas no tempo e no espaço, havendo inclusive uma polêmica em torno da afirmação de que quem é catadora não é marisqueira e, portanto, não teria direito ao seguro-defeso.

Como regula a Instrução Normativa n. 2 do Ministério da Pesca e Aquicultura (MPA), ${ }^{16}$ são pescadores profissionais na pesca artesanal aqueles "que exerçam a pesca como atividade principal e com fins comerciais, fazendo dessa atividade sua profissão e principal meio de vida", sendo ainda necessária a "comprovação de que não há qualquer vínculo empregatício em outra atividade profissional que não seja a de pesca, [...] e a verificação de que não há outra atividade econômica não relacionada diretamente com a atividade de pesca, mesmo que sem vínculo empregatício”.

O conteúdo da lei difere enormemente da realidade descrita pelas mulheres entrevistadas, observada por nós e por diversos autores. Estratégias de pluriatividade $^{17}$ fazem parte do cotidiano dos habitantes do Pontal em razão da sazonalidade da atividade extrativista e da complementaridade entre ocupações. Cotrim e Miguel (2008:14) afirmam que "pescadores na busca pela reprodução social combinam atividades pesqueiras e não pesqueiras". Niederle et al. (2005: 4) reforçam essa constatação afirmando que “[...] há elementos suficientes para identificar o pescador artesanal como uma forma peculiar de produção, a qual se aproxima dos traços gerais que definem a agricultura familiar", sendo a adoção de diferentes estratégias uma prática cotidiana (Mota et al. 2012).

Seguindo o modelo sugerido pela legislação, ficariam de fora todas as afiliadas entrevistadas no nosso estudo de caso, pois elas, sem exceção, realizam diferentes atividades ao longo do ano e em diferentes espaços.

Localmente, a afirmação de que "quem é catadora não é marisqueira" ganha outros contornos, porque a realização de diferentes atividades para garantir a sobrevivência é parte do modo de vida de 100\% das extrativistas entrevistadas. Elas dedicam-se a pelo menos três diferentes atividades para suprir as suas necessidades e as de suas famílias, em diferentes configurações ao longo do calendário produtivo.

No universo das mulheres entrevistadas, as principais questões em debate consistem em saber se a pessoa frequenta ou já frequentou a maré e/ou o mangue e se a pessoa traz marcas no corpo da ida na maré.

“Tem gente que não vai na maré [manguezal], mas recebe. Acho que não devia receber. Tem muitos que não são pescadores e recebem" (E. M. C., 50 anos, extrativista e vendedora de produtos de beleza por catálogos).

"O seguro de algum modo incentivou as pessoas a virar pescador, também porque não tem outra coisa pra fazer no lugar. Ninguém gosta de roça aqui"'(K. R. S. L., 33 anos, marisqueira e pequena comerciante de produtos locais). 
A afirmação das entrevistadas tem como alvo pessoas que, segundo elas, não seriam pescadores e, também, jovens rapazes que passaram a dedicar-se recentemente à pesca e que ainda não trazem as marcas da atividade impressas no corpo, nem conhecem ainda a rotina incessante das marés, por transitarem entre a escola e a atividade recente. Por um lado, parece estar em jogo certa rivalidade entre os que já realizam a atividade há anos e os recentemente iniciados; por outro, há uma rejeição à socialização precoce na "maré", porque todas as entrevistadas afirmam temer a ida dos filhos (crianças e jovens) para o manguezal - segundo elas, local muito perigoso para os inexperientes e mesmo para os mais experientes que evitam ir sozinhos.

“[...] vamos eu e minhas irmãs, nunca fui sozinha, tenho medo de ir só. A gente nunca sabe, pode dar uma dor, uma coisa, ou se cortar. Uma vez, quando eu tinha oito anos, eu fui pescar aratu, minha mãe sempre dizia pra prestar atenção, aí caí dentro de uma baga de ostra, me cortei toda, saiu sangue por cima da lama, minhas irmãs me escutaram chorando, vieram ver, começaram a chorar também, me levaram, nem pude vir pra casa, papai sabia umas rezas de estancar sangue, me trouxeram pra cá, ele rezou, estancou o sangue e ele amarrou um pano. Foi a única vez que me cortei, agora a gente vai pro mangue de sapato" (J. S., 45 anos).

A referência à necessidade de longa experiência no trabalho da pesca como exigência para ter direito ao seguro-defeso, em oposição à inexperiência dos recém-iniciados, repete-se nos diferen- tes discursos. As marcas deixadas no corpo ao longo dos anos, na visão de uma das entrevistadas, deveriam ser um requisito para o reconhecimento da condição de marisqueira oficialmente: "Se qualquer um chegar à colônia é só mostrar o pé preto e todo mundo já sabe, pé preto, a lama penetra, os cortes estão tudo no corpo, olhe aqui as minhas pernas, tudo aqui" (E. M. C., 50 anos, extrativista e vendedora de produtos de beleza por catálogos).

Após mostrar as cicatrizes, compreendidas como marcas do trabalho, e relatar a tensão enfrentada quando um filho que a acompanhava no trabalho de coleta no mangue cortou-se gravemente sem possibilidade de socorro imediato, a mesma entrevistada concluiu: "Tem direito ao defeso só quem faz os documentos, pessoas que pescam e dependem do mangue" (E. M. C., 50 anos, extrativista e vendedora de produtos de beleza por catálogos).

No depoimento, ela demonstra acatar o requisito formal (ter documentos) imposto pelas instituições e exercer atualmente a atividade, muito embora ela mesma quase não a pratique mais por falta de condições físicas. Entretanto, tem dificuldades para entender o processo de afiliação e corrigir os erros que a perseguem por anos em um momento em que já não tem disposição física para aventurar-se por mangues mais distantes onde ainda pode encontrar mariscos. Mesmo assim, afirma esperançosa: "Eu recebi [o seguro-defeso] e depois foi bloqueado por oito anos, agora está saindo de novo" (E. M. C., 50 anos, extrativista e vendedora de 
produtos de beleza por catálogos). Questionada sobre os motivos da interrupção do recebimento, não soube informar. Acredita que tenha sido em decorrência de um problema com uma das carteiras de identificação do pescador.

Mesmo que todas as entrevistadas desenvolvam simultaneamente muitas atividades, elas afirmam que o segurodefeso deve ser para quem "vive da pesca", afirmação que coincide com a legislação, que sugere que os pescadores artesanais estão entre os segurados especiais, considerados aqueles que, "instados individualmente ou em regime familiar", fazem da pesca sua "profissão habitual ou principal meio de vida", desde que respeitadas algumas outras características.

Ter a pesca como principal meio de vida, entretanto, não corresponde à situação atual da entrevistada E. M. C., porque ela não exerce a atividade no momento. Em nossa análise, seu discurso retoma o conteúdo da legislação, mas o amplia quando sugere que o corpo marcado lhe daria direito a uma tardia recompensa na forma de seguro-defeso.

Frequentemente encontramos mulheres que afirmaram ter "se criado na maré", mas que já não a visitam, principalmente pela falta de condições físicas, porque "o mangue acaba com um". Em apenas um caso ouvimos a expressão "eu amo o mangue, sou doida pelo meu mangue".

Se a política do seguro-defeso foi motivada por precauções ambientais e por temor da extensão de direitos trabalhistas, no Pontal ela é associada pelas mulheres ex- trativistas a uma recompensa pelo trabalho árduo, principalmente daquelas que frequentaram o mangue desde jovens.

Nem por isso deixam de existir polêmicas sobre quem teria direito ao segurodefeso, destacando-se dois grupos de interpretação. No primeiro, situam-se os que aceitam o conteúdo proposto pela lei e defendem que apenas os pescadores e as marisqueiras que estão na ativa devem ter direito. No segundo, encontram-se os que o consideram como uma política social para ajudar os mais pobres, que têm dificuldade em obter o necessário à sobrevivência por meio da pesca dada a escassez dos recursos, porque "antigamente tinham cinco redes e hoje cinquenta, tinha vinte pescadores e hoje tem mais de mil” (J. C. P. A, 53 anos, pescador).

"Só quem faz os documentos, pessoas que pescam e dependem do mangue. Tem gente que pesca, tem direito, mas não tem o documento, nem paciência para fazer" (K. R. S. L., 33 anos, marisqueira e pequena comerciante de produtos locais).

"Quando chega a época do defeso, faz a documentação e recebe. Aí só pode pescar quando não está na desova" (E. A. M., 43 anos, extrativista e pequena comerciante).

Independentemente de suas interpretações, todos os entrevistados, inclusive os presidentes das Colônias de Pescadores da região, consideram que a complexidade do funcionamento do seguro-defeso dificulta sua compreensão por parte dos afiliados e pretendentes. As diversas instâncias pelas quais correm os processos, as carteiras 
de pescador e as taxas a serem pagas aparecem nos seus discursos sem nexo umas com as outras. Ademais, para as mulheres extrativistas, é comum não dispor de dinheiro para pagar as viagens às sedes municipais e as taxas necessárias para a afiliação.

\section{USOS DOS RECURSOS DO PAA E DO SEGURO-DEFESO PELAS EXTRATIVISTAS}

Os arranjos instituídos para o uso dos valores provenientes do seguro-defeso e do PAA pelas mulheres extrativistas entrevistadas são diversificados e variam em função de outras rendas (assalariamento temporário, venda de cocadas e produtos de beleza por catálogos) e dos programas de políticas públicas a que tenham acesso, como o Bolsa Família e a Aposentadoria Rural. Em todos os casos, há unanimidade sobre a importância crescente desses recursos para a sobrevivência dos que dependem do extrativismo animal e vegetal em virtude da diminuição dos recursos naturais e, consequentemente, do volume dos produtos a serem vendidos.

Muitas extrativistas utilizam os recursos do seguro-defeso para investir nos instrumentos de pesca e na reforma de suas casas, porque o montante que recebem de uma só vez é considerado muito significativo localmente. Em menor proporção, utilizam parte do seguro para comprar alimentos para a família:

"O dinheiro ajuda bastante porque facilitou as coisas para trabalhar. Muda tanto para o que compra, quanto para o trabalho. Não precisa ir mais todo dia, porque tem rede. Pegando dois, três peixes grandes, sigo tendo para a semana. Se não tiver rede e barco, tem que ir todo dia pescar de mão e aí pegar pouco, tendo que ir todo dia. Vai mesmo pra maré porque tem equipe. $\mathrm{O}$ dinheiro é maior do que pescando" (K. R. S. L., 33 anos, marisqueira e comerciante).

"[...] Com o dinheiro do segurodefeso, eu comprei um barco e motor pra ir mais longe, porque tem os mangues melhores" [frequentados por menos pessoas] (A. S. C., 43 anos, extrativista).

Constatamos com os depoimentos que a própria atividade é intensificada com o suporte oferecido pelos recursos, ou seja, a capacidade de trabalho das extrativistas aumenta.

Diferentemente, os depoimentos indicam que os recursos oriundos do PAA são mais utilizados pessoalmente e na esfera doméstica. Observações indicam um aumento da quantidade de eletrodomésticos adquiridos. Em conversas com entrevistadas, frases do tipo "consigo pagar as minhas contas" e "agora lavo meu cabelo com xampu porque antes era com sabão" foram frequentes. Em nenhum caso constatamos a compra de instrumentos de trabalho ou a mudança do processo de coleta dos frutos, a não ser pela intensificação para ter maior volume e comercializar mais.

Analisamos que as explicações para a diferença nos usos dos recursos podem ser buscadas nos distintos modos de compreensão das atividades como associadas a mulheres ou a homens, que algumas vezes, são interpretadas como 
trabalho ou não. Assim, o extrativismo animal, também praticado pelos homens, é alvo de investimentos para a maior eficiência. Já o vegetal, predominantemente praticado pelas mulheres, sofre mudanças, não nas suas práticas, mas na intensidade da coleta. É importante ressaltar que o manguezal, o mar e o rio permanecem com acesso livre, não obstante a onda de devastação. $\mathrm{O}$ acesso às mangabeiras, ao contrário, está cada vez mais restrito. Assim, os modos de acesso às mangabeiras influem também nos investimentos.

Além da indicação do uso do recurso oriundo do PAA na esfera doméstica, os depoimentos apontaram a eficiência do processo de venda com o aproveitamento de todos os frutos. "A vantagem é que a gente não perde, não vai para feira e ter que jogar fora quando tem muita mangaba. Já cata e entrega aqui mesmo em Pontal e o tanto que catar, 'entrega'. Já tem valor certo" (S. A. S., 35 anos, catadora de mangaba).

Mais raramente, os valores oriundos tanto do PAA quanto do seguro-defeso são uma espécie de "reserva" para ser usada em momentos de maior necessidade, por aquelas que dispõem de alguma fonte mensal ou semanal de renda, como bolsa família ou aposentadoria, ou por algum assalariado, regular ou temporariamente. Uma particularidade chama a atenção: o uso do total ou de parte do recurso da Bolsa Família com as próprias crianças:

"Eu gasto dinheiro com elas, material escolar, calcinha, soutien, pra essa daí que já está moça, é mais com ela que já está mais moça, as outras são menores, dão menos despesas. Com ela, essa, vai o dinheiro todo, as coisinhas pra elas mesmo. Nunca tirei um centavo pra comprar nada pra dentro de casa, nem pra mim nem pra nada" (J. S., 45 anos, extrativista)

"Aí eu compro roupa, chinelo e remédio para os meninos. Entendo que o dinheiro é delas. É um dinheiro que ajuda muito" (K. R. S. L., 33 anos, extrativista e pequena comerciante).

As necessidades cotidianas das crianças e/ou da família são atendidas pela renda mensal e as demais, pelas rendas pontuais. Nas palavras de uma entrevistada, as rendas oriundas dos programas de políticas públicas geram uma espécie de segurança para "não sair desesperada por aí atrás de dinheiro para ter o que comer" (K. R. S. L., 33 anos, extrativista e pequena comerciante).

Tanto o PAA quanto o seguro-defeso significam recursos nas mãos das mulheres cujas consequências, segundo elas, incidem direta ou indiretamente na esfera doméstica sob sua responsabilidade. Talvez por isso, o temor de perder alguma dessas rendas seja tão frequente em seus discursos.

\section{REFLEXÕES FINAIS}

No Pontal, o estímulo inicial para o acesso aos programas de políticas públicas pelas mulheres extrativistas é variável. No caso do PAA, foram a mobilização e a visibilidade das catadoras de mangaba que viabilizaram a participação das mulheres nesse programa. Já no caso do seguro-defeso, 
foi a divulgação local pelo dirigente da Colônia de Pescadores Z4 que incentivou a participação das mulheres. Em ambos os casos, as afiliadas consideram os programas complexos e têm dificuldades para descrevê-los, muito embora compreendam as suas condicionalidades e o funcionamento local.

Quanto à participação das extrativistas nesses programas, os sentidos construídos localmente diferem do proposto na legislação pertinente. No caso do seguro-defeso, vão além do mero desempenho atual da ocupação de pescador ou marisqueira e sugerem incorporar todos aqueles que exerçam ou tenham exercido a ocupação como parte de um modo de vida, o que seria simbolizado pelas marcas deixadas pela dureza da atividade nos corpos. Ao mesmo tempo, rejeitam a participação nesse programa dos jovens ainda sem experiência. No caso do PAA, a universalidade é a tônica, e estratégias locais constroem-se para que todos possam participar do programa, quer seja pela comercialização da mangaba em nome de quem possui a DAP, quer seja pelo recebimento de produtos destinados à suplementação alimentar de modo indiscriminado.

Em relação ao manuseio dos recursos financeiros advindos dos dois programas, as mulheres extrativistas indicam estar sob seu controle, reforçando indicativos de mudanças da percepção quanto ao lugar das mulheres como atores sociais e políticos. Constatamos que elas manejam mais frequentemente os recursos financeiros oriundos do PAA com propósitos individuais e em prol do consumo do grupo doméstico, enquanto o do seguro-defeso é investido em equipamentos para a maior eficiência da produção e em bens duradouros, como na reforma de casas. Tanto os modos de acesso aos recursos, quanto à composição do orçamento com recursos aportados por outras atividades e membros da família influem nessa configuração.

Os recursos recebidos influenciam diretamente as condições objetivas de reprodução. Os arranjos feitos destinam os recursos recebidos mais regularmente (Bolsa Família, aposentadoria e assalariamento) às necessidades cotidianas e aqueles mais esporádicos ao consumo extra (PAA) e a investimentos (seguro-defeso) em função dos montantes recebidos.

Em ambos os casos, o recebimento de recursos e a existência de programas que envolvem prioritariamente mulheres influem nas relações de gênero, porque reforçam a posição das mulheres tanto na esfera doméstica quanto na pública, estando implícito nessa última o universo do trabalho. Consequentemente, verifica-se o reposicionamento das mulheres em ambas as esferas e uma mudança da percepção de seus direitos.

Tanto os recursos do seguro-defeso, quanto os do PAA influem na atribuição do status de trabalho às atividades extrativistas porque geram remuneração, monetariamente quantificada. Ademais, inserem-se no quadro de reconhecimento público.

As conclusões indicam que ambos os programas proporcionam oportunidades 
de melhoria da renda e da percepção da condição social das suas afiliadas. Diferenciam-se, entretanto, quanto ao uso dos recursos: temporariamente interditados na pesca e estimulados na coleta de mangaba. Em relação aos sentidos construídos localmente, o PAA é considerado uma relação mais próxima à mercantil, pois exige contrapartida contratual. $\mathrm{O}$ seguro-defeso assemelha-se a uma relação assistencial, "uma ajuda" do governo para os pobres, com uma contrapartida que depende da consciência de cada um. Mesmo assim, os recursos financeiros do segundo são mais frequentemente usados para investimentos na produção em decorrência do maior volume recebido.

No que diz respeito aos direitos conquistados mais recentemente pelas mulheres rurais, informações do Ministério do Desenvolvimento Social e Combate à Fome (MDS 2011) mostram que, nas modalidades de Compra da Agricultura Familiar com Doação Simultânea e Compra Direta Local com Doação Simultânea, será exigida a participação de pelo menos $40 \%$ de mulheres do total de produtores. Para as modalidades Incentivo à Produção e ao Consumo de Leite (PAA Leite) e Formação de Estoques, o percentual será de 30\%. A garantia desses percentuais representa claramente uma conquista. Em contrapartida, regras de funcionamento local do PAA foram redefinidas e condicionam a participação das associações ao aval dos prefeitos municipais. ${ }^{18}$ Não obstante as conquistas, avanços e recuos persistem marcando os novos termos do debate sobre a inserção das mulheres nos programas de políticas públicas no espaço rural.

\section{AGRADECIMENTOS}

Ao Conselho Nacional de Desenvolvimento Científico e Tecnológico (CNPq) do Ministério da Ciência e Tecnologia (MCT), à Empresa Brasileira de Pesquisa Agropecuária (Embrapa) e à Universidade Federal do Pará (UFPA) pelo financiamento da pesquisa.

\section{NOTAS}

${ }^{1}$ Segundo as autoras, foi somente a partir de 1985 que começaram a surgir iniciativas de políticas públicas que incorporam componentes de gênero a suas ações substituindo aquele "cidadão indiferenciado" a quem se dirigiam. Dentre as primeiras ações, elas destacam o Programa de Apoio à Mulher em 1985, do Ministério da Agricultura, o Projeto de Apoio à Organização da Mulher Rural em 1988, do Sistema Brasileiro de Assistência Técnica e Extensão Rural (Sibrater), e a Previdência Rural, a partir de 1992.

${ }^{2}$ Em algumas partes deste artigo fazemos referência ao Programa Bolsa Família por ser constantemente mencionado pelas entrevistadas e relacionado localmente com os programas aos quais elas têm acesso. Outra pesquisa sobre o Bolsa Família está sendo por nós realizada.

${ }^{3}$ Exemplos são: a Instrução Normativa INCRA n. ${ }^{\circ}$ 38, o Decreto n. ${ }^{\circ}$ 6040/2007, bem como o Programa Bolsa Família, o Programa de Promoção da Igualdade de Gênero, Raça e Etnia (PPIGRE), o Programa Nacional de Documentação da Trabalhadora Rural, do Ministério do Desenvolvimento Agrário (MDA), o Programa de Apoio ao Agroextrativismo, do Ministério do Meio Ambiente (MMA), a Política de Garantia de Preço Mínimo para Produtos da Sociobiodiversidade (PGPM) e o Plano 
de Ação Nacional para o Fortalecimento do Extrativismo, sendo uma das primeiras ações a promoção de Assistência Técnica e Extensão Rural para o Extrativismo.

${ }^{4}$ As mesmas mulheres praticam as duas atividades. Ora elas utilizam uma autodesignação, ora utilizam outra, o que atualiza a noção de que as identidades não são instâncias fixas, imutáveis ou definitivas, sendo, na maior parte das vezes, situacionais e temporárias (Hall 2000; Silva 2000; Uriarte 2001). O pertencimento a uma coletividade e a formação de uma categoria em função dos interesses são partes do mesmo processo de identificação, como corrobora Jenkins (2008:7).

5 "Taipa" é o processo de construção de paredes com barro em cima de um traçado de ripas ou varas, também chamado de "pau a pique".

${ }^{6}$ Os proprietários de estabelecimentos situados no povoado Pontal, em geral, residem nas cidades vizinhas e usam esses estabelecimentos como segunda residência ou para a exploração da cultura do coqueiro.

${ }^{7}$ Instituído pelo artigo 19 da Lei n. ${ }^{\circ} 10.696$, de 2 de julho de 2003, e regulamentado pelo Decreto n. ${ }^{\circ} 4.772$, de 2 de julho de 2003.

${ }^{8}$ Segundo a Lei n. ${ }^{\circ} 11.326$, de 24 de julho de 2006, que estabelece as diretrizes para a formulação da Política Nacional da Agricultura Familiar e Empreendimentos Familiares Rurais, são considerados os agricultores familiares os extrativistas que atendam simultaneamente aos requisitos previstos nos incisos II, III e IV: utilizem predominantemente a mão de obra da própria família nas atividades econômicas do seu estabelecimento ou empreendimento, tenham renda familiar predominantemente originada de atividades econômicas vinculadas ao próprio estabelecimento ou empreendimento e dirijam seu estabelecimento ou empreendimento com sua família.
${ }^{9}$ Um vereador membro da Cooperativa de Produção, Comercialização e Prestação de Serviços dos Agricultores Familiares de Indiaroba e Região (Cooperafir) que na ocasião participava do PAA com agricultores familiares com 10 produtos (abacaxi, banana, batata-doce, cebolinha, coco verde, coco seco, coentro, laranja, maracujá, raiz de mandioca com e sem casca), e o presidente da Associação de Moradores do Povoado Pontal e Periferia.

${ }^{10}$ Destina-se à aquisição de produtos de origem agrícola, pecuária e extrativa, oriundos da agricultura familiar, visando a formação de estoques ou a doação às populações em situação de risco alimentar atendidas por programas sociais de caráter governamental ou não governamental. Os produtores beneficiários deverão estar organizados em grupos formais e estar enquadrados segundo os critérios estabelecidos pelo programa. Nos casos de doação simultânea, a entrega dos produtos deverá obedecer a um cronograma apresentado na Proposta de Participação. O controle social das doações dar-se-á por meio do envolvimento do Conselho de Segurança Alimentar (municipal ou estadual) ou de um organismo similar. Essa modalidade também é operacionalizada pela Conab.

${ }^{11}$ Em 2010 foram as seguintes: Associação de Moradores do Povoado Convento, Associação do Menor Aprendiz, Associação dos Produtores Rurais do Povoado Félix, Associação pela Cidadania dos Pescadores de Terra Caída e Associação Sergipana de Desenvolvimento Comunitário e Resgate da Cidadania.

${ }^{12}$ Presidente da Associação de Moradores do Povoado Pontal e Periferia e agente de saúde.

${ }^{13}$ A expressão "trabalhador rural” é usada pelos sindicatos que representam as pessoas que trabalham no meio rural e que 
organizam os assalariados e os agricultores no mesmo "sindicato dos trabalhadores rurais". Em muitas regiões brasileiras, os agricultores familiares constituem a maior parte dos sócios.

${ }^{14}$ Lei n. ${ }^{\circ} 11.959$, de 29 de junho de 2009.

${ }^{15}$ Segundo o Código de Conduta e Boas Práticas da Associação Brasileira de Criadores de Camarão (ABCC 2012a: 46), "Os efluentes dos viveiros e os diversos resíduos sólidos são os dois elementos que requerem manejo especial para que sejam preservadas a qualidade ambiental e a sanidade dos camarões na própria fazenda e nas áreas vizinhas". "A neutralização do Metabissulfito de sódio é essencial para a proteção do meio ambiente" (ABCC 2012b:38).

${ }^{16}$ Publicada em 26 de novembro de 2011.

17 A pluriatividade "refere-se a situações sociais em que os indivíduos que compõem uma família com domicílio rural passam a se dedicar ao exercício de um conjunto variado de atividades econômicas e produtivas, não necessariamente ligadas à agricultura ou ao cultivo da terra, e cada vez menos executadas dentro da unidade de produção" (Schneider 2003).

${ }^{18}$ Este documento, no seu último ponto, exige: "Declaração do gestor local de que a entidade realiza ações de assistência social de forma gratuita" (BRASIL 2013:2).

\section{REFERÊNCIAS}

ABCC. 2012a. Código de conduta e de boas práticas de manejo para as fazendas de engorda de camarão marinho. 2. ed. Natal: Associação Brasileira de Criadores de Camarão.

ABCC. 2012b. Boas práticas de manejo e biosseguransa para a carcinicultura marinha nacional. Natal: Associação Brasileira de Criadores de Camarão.
Almeida, M. da G. 1991. Atividades Produtivas, in Textos para a história de Sergipe. Editado por D. M. F. L.Diniz, pp. 61-125. Aracaju: EDUFS.

BRASIL. 2013. Como solicitar a certificação. Brasília: Ministério do Desenvolvimento Social e Combate à Fome (MDS), Secretaria Nacional de Assistência Social (SNAS), Departamento da Rede Socioassistencial Privada do Sistema Único de Assistência Social.

Cardoso, L. F. C. 2008. A constituição local: direito e território quilombola na comunidade de Bairro Alto, na Ilha de Marajó - Pará. Tese de Doutorado. Programa de Pós-graduação em Antropologia Social, Universidade Federal de Santa Catarina, Florianópolis, Brasil.

Carvalho, M. E. S. e A. L. Fontes. 2007. A Carcinicultura no espaço litorâneo Sergipano. Revista da Fapese 3(1): 87-112.

Castro, E. 1997. Território, biodiversidade e saberes de populações tradicionais, in Faces do Trópico Úmido: conceitos e questões sobre desenvolvimento e meio ambiente. Editado por E. Castro e F. Pinton, pp. 263-283. Belém: Cejup.

CONAB. 2007. Programa de Aquisição de Alimentos: renda para quem produz e comida na mesa de quem precisa. Brasília: Companhia Nacional de Abastecimento. Disponível em: <http://www.mda.gov.br/portal/saf/ arquivos/view/paa/Cartilha_PAA.pdf $>$. Acesso em: 13 fev. 2012.

Cotrim, D. C. e L. A. Miguel. 2008. Pluriatividade: uma noção aplicável em pescadores artesanais?, in Encontro de Economia Gaúcha 4, Anais. Porto Alegre: PUCRS, FEE.

Delgado, G., J. C. P. R. da Conceição, e J. J. Oliveira. 2005. Avaliação do Programa de Aquisição de Alimentos da Agricultura Familiar (PAA). Texto para Discussão 1145. Brasília: IPEA.

Fraser, N. 2003. Soziale gerechtigkeit im zeitalter der identitätspolitik, in Umverteilung oder Anerkennung? Eine politisch-philosophische Kontro- 
verse. Editado por N. Fraser e A. Honneth. Frankfurt: Suhrkamp Verlag.

Grisa, C., J. C. Schmitt, L. F. Mattei, R. S. Maluf e S. P. Leite. 2009. O Programa de Aquisição de Alimentos (PAA) em perspectiva: apontamentos e questões para o debate. UFFRJ/ CPDA. Disponível em: <http://oppa. net.br/acervo/publicacoes/Pesquisa_ AABROPPA_Texto_PAA_versao_livro. pdf> Acesso em: 13 fev. 2012.

Hall, S. 2000. Quem precisa da identidade?, in Identidade e diferença: a perspectiva dos estudos culturais. Organizado por T. T. Silva, pp. 103-133. Petrópolis: Vozes.

Heredia, B. e R. Cintrão. 2006. Gênero e acesso a políticas públicas no meio rural brasileiro. Revista Nera 9(8):1-21.

Jenkins, R. 2008. Social Identity. London: Routledge.

Joventino, F. K. P. 2008. A sustentabilidade da carcinicultura no município de FortimCE, com ênfase nos aspectos sociais, ambientais e tecnológicos. Revista Pós Ciências Sociais 5(9/10):195-199.

Lourenço, C. F., J. A. S. Henkel, e M. C. Maneschy. 2006. A seguridade social para pescadores artesanais do Brasil: estudo de caso no Pará. Chennai: ICFS.

MDS. 2011. Mulheres terão acesso mais fácil ao Programa de Aquisição de Alimentos. Disponível em: <http://www.mds.gov.br/ saladeimprensa/noticias/2011/agosto/ mulheres-terao-acesso-mais-facil-ao-programa-de-aquisicao-de-alimentos $>$ Acesso em: 13 mai. 2013.

Moraes, S. C. 2001. Colônias de pescadores e a luta pela cidadania, in Congresso Brasileiro de Sociologia 10, Fortaleza: UFC.

Moreira, H. C. L., E. F. Scherer e S. M. Soares. 2010. O seguro defeso do pescador artesanal: políticas públicas e o ritmo das águas na Amazônia, in Congreso Lati- noamericano de Sociología Rural 8, Associação Latino-Americana de Sociologia Rural (ALASRU), Ipojuca-PE. Disponível em: <http://www.alasru.org/wp-content/ uploads/2011/07/GT9-Helane-Moreira. pdf>. Acesso em: 9 mar. 2013.

Mota, D. M. da, J. F. da Silva Júnior, H. Schmitz e R. F. de A. Rodrigues (Eds). 2011a. A mangabeira. As catadoras. O extrativismo. Belém: Embrapa.

Mota, D. M. da, H. Schmitz e J. F. da Silva Júnior. 2011b. Conflito e consenso pelo acesso aos recursos naturais no extrativismo da mangaba. Antropolitica 31:123-146.

Mota, D. M. da, H. Schmitz, J. F. da Silva Júnior, N. M. Porro e T. C. V. de Oliveira. 2012 Programa de Aquisição de Alimentos: Possibilidade de Conservação dos Recursos de Uso Comum em Comunidade Extrativista? in Encontro da Associação $\mathrm{Na}$ cional de Pós-Graduação e Pesquisa em Ambiente e Sociedade (Anppas) 6, Belém.

Müller, A. L., M. A. V. Fialho e S. Schneider. 2007. A inovação institucional e a atuação dos atores locais na implementação do Programa de Aquisição de Alimentos no Rio Grande do Sul. Sociedade e Desenvolvimento Rural 1: 1. Disponível em: <http:// www.inagrodf.com.br/revista/index.php/ SDR>. Acesso em: 13 fev. 2012.

Niederle, P. A., F. C. dos Anjos, C. Grisa, N. V. Caldas e E. P. Schneider. 2005. Pluriatividade e pesca artesanal: o caso da Colônia Z-3 em Pelotas, RS, in Congresso da Sociedade Brasileira de Economia, Administração e Sociologia Rural 43. Ribeirão Preto: FEA-RP, USP.

Paulilo, M. I. S. 2012. A inadequação das políticas públicas no aumento da satisfação e do bem-estar das mulheres rurais, in World Congress of Rural Sociology 8. Lisboa: International Rural Sociology Association (IRSA), Universidade Técnica de Lisboa, 
Instituto Superior de Ciências Sociais e Política.

Porro, N., I. Veiga e D. M. da Mota. 2011. Traditional communities in the Brazilian Amazon and the emergence of new political identities: the struggle of the quebradeiras de coco babaçu - babassu breaker women. Journal of Cultural Geography 28(1):123-146.

Rocha, M. M. L. 2012. Conflitos sociais pelo acesso aos recursos: o extrativismo da mangaba (Hancornia speciosa Gomes) no Povoado Pontal/Sergipe. Dissertação de Mestrado. Programa em Agriculturas Familiares e Desenvolvimento Sustentável, Universidade Federal do Pará, Belém, Brasil.

Schmitz, H., D. M. da Mota, J. F. da Silva Júnior e N. B. de Jesus. 2010. Conflitos sociais em debate: o caso das catadoras de mangaba no Nordeste e Norte do Brasil. Revista Estudos de Sociologia 16(1):157-178.

Schneider, S. 2003. Teoria social, agricultura familiar e pluriatividade. Revista Brasileira de Ciências Sociais 18(51):99-121.

Siliprandi, E. e R. Cintrão. 2011. As mulheres agricultoras e sua participação no Programa de Aquisição de Alimentos (PAA). 27p. Disponível em: <http://www.iica.int/Esp/regiones/sur/brasil/Lists/DocumentosTecnicosAbertos/Attachments/310NEAD. pdf>. Acesso em: 28 nov. 2011.

Silva, T. T. 2000. A produção social da identidade e da diferença, in Identidade e diferença: a perspectiva dos estudos culturais. Organizado por T. T. Silva, pp. 73-102. Petrópolis: Vozes.

Teixeira, G. S. e P. R. Abdallah. 2008. Política de seguro-desemprego ao pescador artesanal: assistencialismo ou incentivo?, in Congresso da Sociedade Brasileira de Economia, Administração e Sociologia Rural 46. Rio Branco: FIRB.
Uriarte, U. M. 2001. A via das máscaras: identidades e identificações na cidade, in As ciências sociais: desafios do milênio. Organizado por V. Gico, A. Spinelli e P. Vicente, pp. 15-31. Natal: EDUFRN.

Vieira, D. L. M. e R.F.A. Rodrigues. 2009. Mapa do extrativismo da mangaba em Sergipe: ameaças e demandas. Aracaju: Embrapa Tabuleiros Costeiros.

Recebido em 19/05/2013.

Aprovada em 12/07/2013. 